\title{
An added boost in pyrogenic carbon when wildfire burns forest with high pre-fire mortality
}

\author{
Anna C. Talucci, ${ }^{1,}$ (D), Lauren M. Matosziuk ${ }^{3}$, Jeff A. Hatten ${ }^{3}$ and Meg A. Krawchuk ${ }^{2}$
}

\begin{abstract}
Background: Wildfires produce pyrogenic carbon (PyC) through the incomplete combustion of organic matter, and its chemical characterization is critical to understanding carbon (C) budgets and ecosystem functions in forests. Across western North American forests, fires are burning through landscapes with substantial tree mortality from insect outbreaks, often referred to as short-interval disturbances. These short-interval disturbances often result in beetle-killed snags (snags that subsequently burn) that are heavily charred, while their fire-killed (alive at time of fire) counterparts are lightly charred. We investigated whether the chemical signature of PyC on heavily charred beetle-killed snags differs from lightly charred fire-killed snags.

Results: We evaluated differences in PyC chemical concentrations and condensation on beetle-killed $(n=3)$ and fire-killed snags $(n=3)$ with the benzene polycarboxylic acid (BPCA) molecular marker method. Beetle-killed snags exhibited over five times the grams of BPCA per kilogram of $C$, and over seven times the grams of BPCA per kilogram of material compared to fire-killed snags, indicating higher concentrations of PyC.

Conclusion: PyC concentrations were greater in samples from beetle-killed snags compared to fire-killed snags, pointing to an important compound effect from the interaction of beetle outbreak and wildfire in forest ecosystems. While this study was limited to a single fire event and sampling in individual trees, it provides insight into PyC on snags with different disturbance histories. The abundance of heavily charred snags from a fire burning through landscapes with high levels of existing mortality from drought, insect outbreaks, and previous wildfire events is becoming a more common legacy for contemporary western North American forests. Accordingly, the distinct wood-based PyC legacy could influence ecosystem functions: C sequestration, water purification, soil nutrient supply, and resources for wildlife.
\end{abstract}

Keywords: bark beetles, benzene polycarboxylic acid (BPCA) method, biogeochemical cycles, biologic function, char, lodgepole pine, Oregon, short-interval disturbances, structural legacies

\footnotetext{
* Correspondence: actalucci@gmail.com

'Department of Geography, Colgate University, 13 Oak Drive, Hamilton, New

York 13346, USA

2Department of Forest Ecosystems and Society, Oregon State University,

3100 SW Jefferson Way, Corvallis, Oregon 97331, USA

Full list of author information is available at the end of the article
}

\section{Springer Open}

(c) The Author(s). 2020 Open Access This article is licensed under a Creative Commons Attribution 4.0 International License, which permits use, sharing, adaptation, distribution and reproduction in any medium or format, as long as you give appropriate credit to the original author(s) and the source, provide a link to the Creative Commons licence, and indicate if changes were made. The images or other third party material in this article are included in the article's Creative Commons licence, unless indicated otherwise in a credit line to the material. If material is not included in the article's Creative Commons licence and your intended use is not permitted by statutory regulation or exceeds the permitted use, you will need to obtain permission directly from the copyright holder. To view a copy of this licence, visit http://creativecommons.org/licenses/by/4.0/. 


\section{Resumen}

Antecedentes: Los incendios de vegetación producen carbón pirogénico (PyC) mediante la combustión incompleta de la materia orgánica, y su caracterización química es crítica para el entendimiento de los depósitos de carbono (C) y el funcionamiento de los ecosistemas forestales. A través de los bosques del oeste de Norteamérica, los incendios están quemando en paisajes que contienen una sustancial mortalidad de árboles debido al ataque de insectos, comúnmente referidos como disturbios de intervalos cortos. Estos disturbios de intervalos cortos resultan frecuentemente en árboles muertos en pie (snags) debido al ataque de estos insectos; luego estos árboles se queman y son altamente carbonizados, mientras que árboles asociados, pero sin ataque de insectos y vivos al momento del fuego, son levemente carbonizados por el fuego. Investigamos si la firma química del carbón pirogénico (PyC) de los árboles muertos en pie por el ataque de insectos y luego altamente carbonizados por efectos del fuego difieren de aquellos muertos en pie solo por el fuego y levemente carbonizados.

Resultados: Evaluamos las diferencias en la concentración química y condensación en árboles muertos por ataques de insectos $(n=3)$ y por el fuego $(n=3)$ mediante el método del marcador molecular que usa el ácido policarboxílico-bencénico (BPCA). Los árboles muertos en pie exhibieron más de cinco veces los gramos de BPCA por kilogramo de C, y por encima de siete veces los gramos de BPCA por kilogramo de material comparado con árboles muertos solo por la acción del fuego, indicando esto altas concentraciones de PyC.

Conclusiones: Las concentraciones de PyC fueron mayores en muestras de árboles muertos en pie por ataques de insectos más fuego, que por solo la acción del fuego, apuntando a un efecto compuesto de interacción entre los ataques de insectos y fuegos en ecosistemas forestales. Aunque este estudio estuvo limitado a un solo evento de fuego y el muestreo de árboles individuales, permite visualizar la formación de PyC en árboles muertos en pie que provienen de distintas historias de disturbios. La abundancia de muertos en pie altamente carbonizados a través de paisajes quemados con altos niveles de mortalidad previa por sequía, ataques de insectos y eventos previos de fuego se está transformando en un legado común para los bosques contemporáneos del oeste de Norteamérica. De acuerdo con esto, las diferencias en el legado del carbón pirogénico contenido en esa madera pueden influenciar las funciones ecosistémicas como el secuestro de C, la purificación del agua, la provisión de nutrientes, y los recursos para la fauna silvestre.

\author{
Abbreviations \\ C: $\quad$ Carbon \\ PyC: Pyrogenic Carbon \\ BPCA: Benzene PolyCarboxylic Acid \\ $\mathrm{NaOH}$ : sodium hydroxide \\ $\mathrm{HCl}$ : hydrochloric acid \\ $\mathrm{H}_{3} \mathrm{PO}_{4}$ : phosphoric acid \\ B6CA: Benzene hexaCarboxylic Acid
}

\section{Background}

Wildfires play an important role in carbon $(C)$ cycles by releasing large amounts of $\mathrm{C}$ into the atmosphere (Campbell et al. 2007; Randerson et al. 2012) and simultaneously sequestering $\mathrm{C}$ in the form of pyrogenic $\mathrm{C}$ (PyC), a form of $\mathrm{C}$ resistant to degradation (Schmidt et al. 2001; Singh et al. 2012). The formation of PyC (sometimes referred to as black $\mathrm{C}$, charcoal, and pyrogenic organic matter) by wildfire is the product of incomplete combustion of organic matter (Bird et al. 2015; Santín et al. 2015; Pingree and DeLuca 2017). Higher temperatures and extended periods of heating generally produce organic matter with more $\mathrm{PyC}$ and a greater degree of aromatic condensation (McBeath et al. 2011; Schneider et al. 2013; Bird et al. 2015). This thermally altered organic matter displays relatively longer turnover times compared to unburned C pools, as it interacts with its environment (Masiello 1998; Schmidt et al. 2001; Torn et al. 2005; Singh et al. 2012; Pingree and DeLuca 2017). PyC is recognized as contributing important functions to forest ecosystems (Pingree and DeLuca 2017) and is increasingly accepted as an important component of global C budgets (Jones et al. 2019). When wildfire burns through forest stands with substantial tree mortality from a previous disturbance such as insect outbreaks followed by wildfires (Raffa et al. 2008, Flannigan et al. 2009, Bentz et al. 2010), heavily charred snags are common (Makoto et al. 2012; Harvey et al. 2014; Talucci and Krawchuk 2019), with a distinct visual appearance. It is important to quantify the molecular structure of this PyC pool to understand how these overlapping disturbances (i.e., short-interval disturbances) affect biogeochemical cycling in forest ecosystems.

The chemical structure of $\mathrm{PyC}$ is expressed across a continuum that includes a wide range of thermally altered material that can be quantified with numerous methods, including benzene polycarboxylic acid (BPCA) analysis. The variety in $\mathrm{PyC}$ ranges from slightly charred biomass that turns over in the environment relatively 
quickly, to highly condensed aromatic material, such as charcoal, that may remain in the environment for centuries to millennia (Schmidt et al. 2001; Singh et al. 2012; Bird et al. 2015). During a fire, increasing temperatures can transform the molecular structure of organic matter into benzene rings that fuse to form interconnected aromatic structures that may eventually condense into extended aromatic sheets, as demonstrated during heating in muffle-furnace experiments (McBeath et al. 2011). There are multiple methods in various stages of refinement used for differentiating $\mathrm{PyC}$ and non-PyC in different types of samples (Hammes et al. 2007). A fairly common and robust measure of $\mathrm{PyC}$ is a molecular marker method, BPCA analysis, that quantifies the amount of PyC as the proportion of $\mathrm{C}$ (PyC : $\mathrm{kg} \mathrm{C}$ ) or mass (PyC : $\mathrm{kg}$ material) in a sample (Dittmar 2008; Wiedemeier et al. 2016). In addition, this method evaluates the degree of aromatic condensation using the Aromatic Condensation Index (ACI), the ratio of BPCAs formed from rings in which all six $\mathrm{C}$ molecules are bound to other benzene rings (B6CAs) to the total BPCA content (Schneider et al. 2010; Schneider et al.
2011; Schneider et al. 2013). Hammes et al. (2007) noted that the BPCA method captures a large range of PyC, from the least altered charcoal to highly aromatic and condensed soot. The BPCAs are only molecular markers of $\mathrm{PyC}$, that depend on the degree of condensation and, in general, BPCA analysis is considered robust but underestimates the amount of $\mathrm{PyC}$ in a sample (Hammes et al. 2007). The ACI method provides additional important detail by focusing on quantification of the more complex, condensed B6CA component of the BPCA content (Schneider et al. 2010; Schneider et al. 2011; Schneider et al. 2013).

When wildfire burns through forest stands with substantial snags (i.e., existing standing dead trees such as from previous insect outbreaks; Harvey et al. 2014; Talucci and Krawchuk 2019), pre-burns (Donato et al. 2016; Ward et al. 2017), or windthrow (Buma et al. 2014), the charring on stems of trees often has an appearance distinct from burned live trees (e.g., Fig. 1; Makoto et al. 2012; Donato et al. 2016; Talucci and Krawchuk 2019). However, the molecular signature of $\mathrm{PyC}$ on these charred snags has not been quantified.

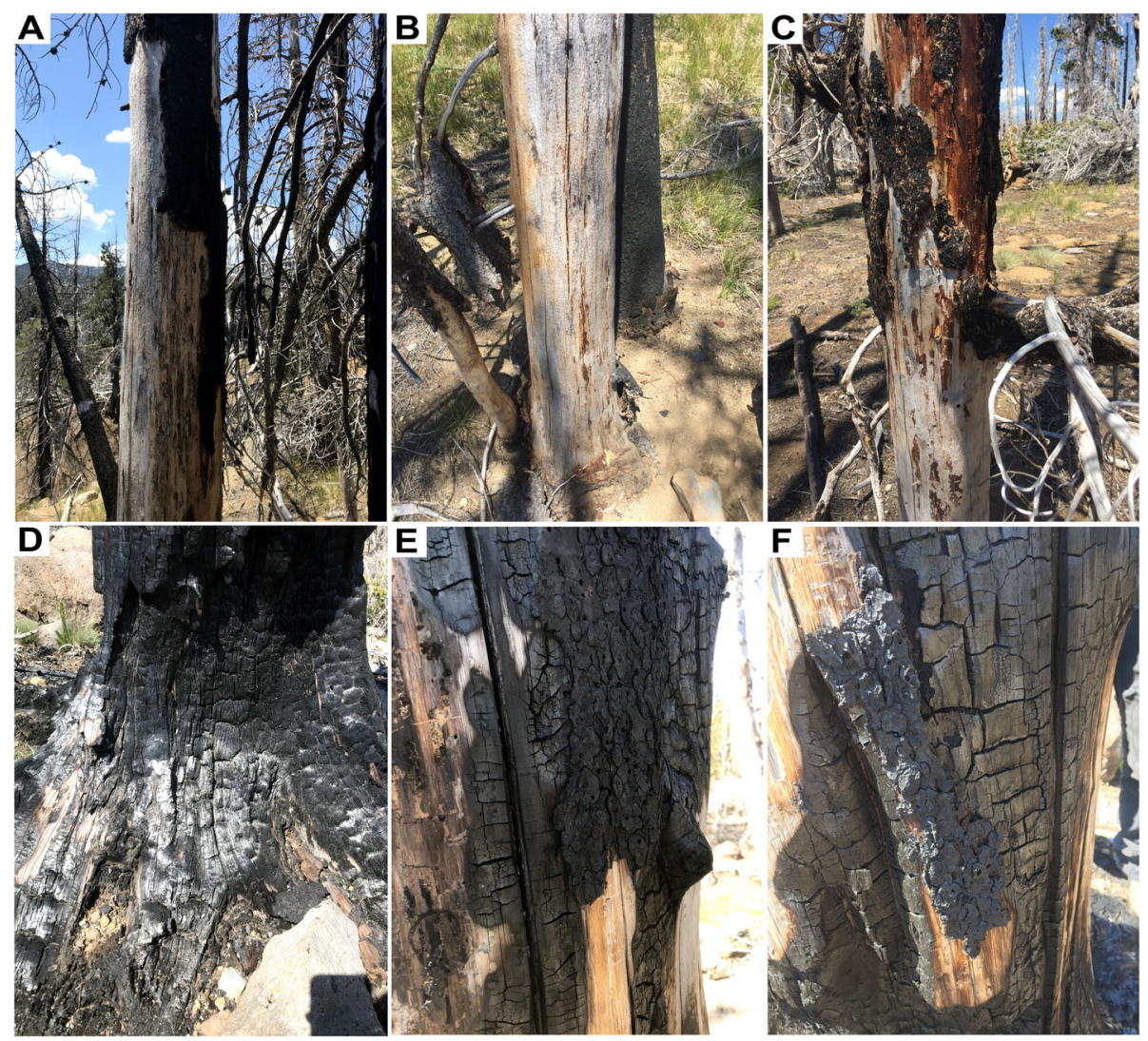

Fig. 1 Beetle-killed and fire-killed snags from the Pole Creek Fire (2012), Oregon, USA, sampled for pyrogenic carbon analyses in June 2018. (A, B, and $\mathbf{C}$ ) Charred bark on fire-killed snags with exposed unburned wood, demonstrating lighter charring. (D, E, and F) Charred bark and wood on beetle-killed snags that had evidence of mountain pine beetle activity (i.e., J-shaped galleries) and were considered to be dead before fire, demonstrating heavy charring. Photos were taken during sampling in June 2018. Photographer credit: L. Matosziuk and A. Talucci 
Snags can ignite faster and at lower temperatures than live trees (Stockstad 1979) due to reduced moisture content (Campbell et al. 2007). Snags can experience smoldering and glowing combustion that leads to prolonged burning (Hyde et al. 2011) as well as more biomass consumption and heavy charring (Donato et al. 2009; Hyde et al. 2011; Harvey et al. 2014; Donato et al. 2016; Talucci and Krawchuk 2019). Recent evaluations of PyC from snags that subsequently burned are primarily based on visual estimates of char coverage (Donato et al. 2009; Makoto et al. 2012; Buma et al. 2014; Santín et al. 2016; Ward et al. 2017). A handful of studies have performed molecular analyses to understand the elemental components of char formed by wildfire alone (Schneider et al. 2013; Santín et al. 2015; Uhelski and Miesel 2017), which can improve understanding of the PyC contribution to the environment (Santín et al. 2016). However, understanding the molecular or elemental structure of char generated by short-interval beetle-fire disturbances, where old snags are subsequently burned, is key to elucidating its role in the $\mathrm{C}$ cycle.

Here we aimed to evaluate differences in $\mathrm{PyC}$ chemical concentrations and condensation in beetle-killed snags and fire-killed snags. Beetle-killed snags refer to trees killed by mountain pine beetles (Dendroctonus ponderosae Hopkins) that subsequently burned during a wildfire; whereas fire-killed snags refer to trees alive at time of fire that were killed by the fire event. We predicted that surface samples from beetle-killed snags, which typically show a heavily charred appearance, would produce more PyC per $C$ and mass than that associated with fire-killed snags, which typically have lightly charred bark. Further, we predicted that the PyC associated with beetle-killed snags would have a more condensed chemical structure, resulting in a longer-lasting $\mathrm{PyC}$ legacy on the landscape.

\section{Methods}

\section{Study area}

In 2012, the Pole Creek Fire burned through forests dominated by lodgepole pine (Pinus contorta var. murrayana [Balf.] Engelm.) in the Deschutes National Forest of the eastern Cascade Mountains of Oregon, USA. These forests had substantial pre-fire mortality from mountain pine beetles (Agne et al. 2016), estimated at 61 to 74 dead trees per hectare (ADS 2005). The area sampled was chosen based on ease of access and was outside the nearby Three Sisters Wilderness boundary.

\section{Sample collection}

On 19 June 2018, we collected surface samples from three beetle-killed snags and three fire-killed snags from the area burned by the Pole Creek Fire. Snags were opportunistically selected from within an area of moderate to high burn severity based on satellite image analysis using the differenced Normalized Burn Ratio (dNBR) acquired from Monitoring Trends in Burn Severity (Eidenshink et al. 2007; MTBS 2016), and an area of substantial outbreak mortality based on the Aerial Detection Surveys (McConnell et al. 2000; ADS 2005).

In the field, the samples came from materials retained on the beetle-killed or fire-killed snags. Due to the sixyear lag between the fire event and sampling period, the bark had started to slough off the snags, with substantial amounts on the ground. Beetle-killed snags were differentiated from fire-killed snags based on an initial visual inspection for substantial mountain pine beetle activity, using methods established by Harvey et al. (2013), and used in Talucci and Krawchuk (2019). The method identifies previous bark beetle activity, and infers mortality, based on visible exit holes on bark and removing the bark to identify J-shaped galleries in the cambium. We did not sample snags that were heavily charred on the full surface area of the stem since this removes evidence of beetle activity, although it is likely that these snags were dead at the time of fire from beetle activity or some other agent of mortality. Notably, Makoto et al. (2012) also used heavily charred snags to infer reduced moisture levels due to mortality from beetle attacks. We visually differentiated between bark and wood and collected samples of bark and wood on the base $(0$ to $1 \mathrm{~m}$ in height) of each snag $(n=6)$. On the three beetle-killed snags, we collected charred material directly from exposed sections of wood and bark on each snag (Fig. 2). On the three fire-killed snags, we collected charred material directly from exposed bark, and wood was sampled from underneath the most charred section of bark since no wood was directly exposed during the fire. This sample location was assumed to be the most thermally altered wood material on the fire-killed snag (Fig. 2) and most appropriate for comparison with wood samples from the beetle-killed snags. These samples were collected by scraping approximately $15 \mathrm{~mL}$ solid equivalent of each material (i.e., bark and wood) with a knife and placing it into a resealable plastic bag. Samples were acquired from the surface material of each type (i.e., bark and wood) about 1 to $3 \mathrm{~mm}$ in depth and covering 1 to $5 \mathrm{~cm}$ in surface area, dependent on the available material.

\section{Sample preparation and procedure}

At the lab, samples were dried overnight at $50{ }^{\circ} \mathrm{C}$ and ground using a ball mill. Two of the bark samples, which came from fire-killed snags, contained sap residue, which made them tacky and difficult to homogenize. These two samples were dried at $50{ }^{\circ} \mathrm{C}$ for an additional three days, and then were flash-frozen in liquid nitrogen and ground into a fine powder with a mortar and pestle. 


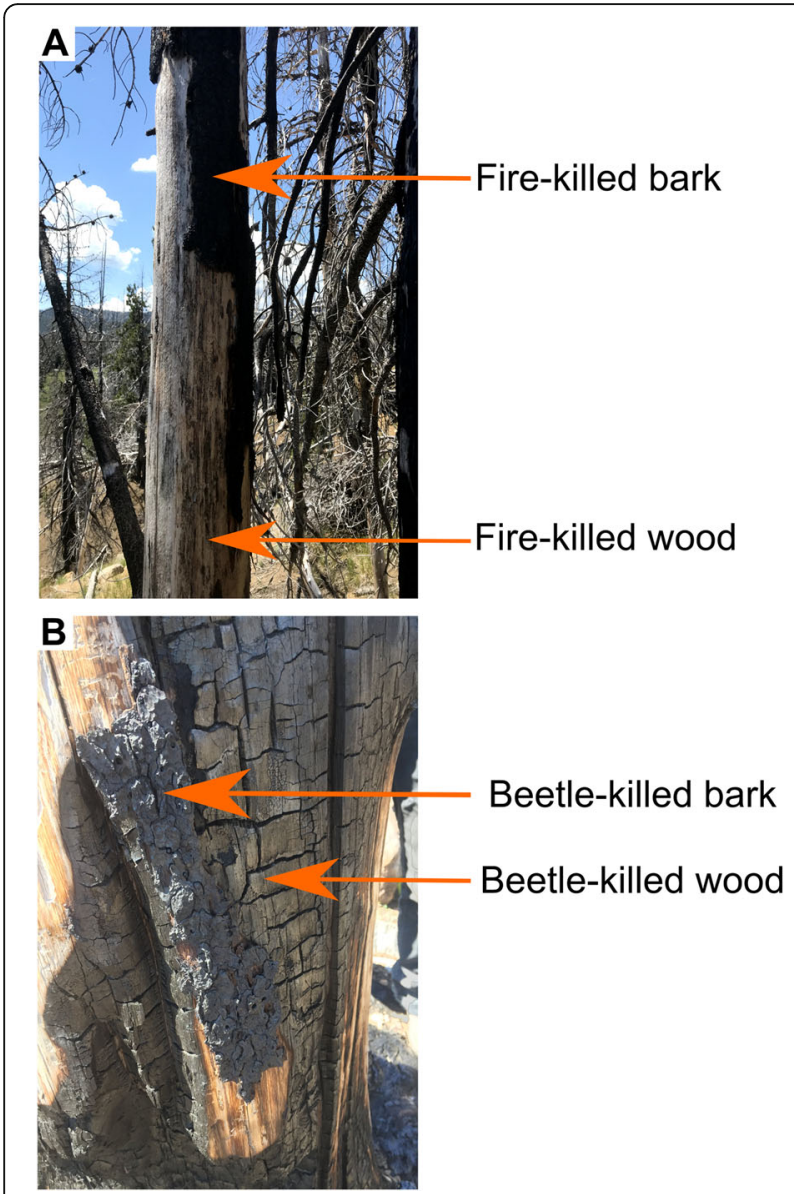

Fig. 2 Samples taken for pyrogenic carbon analyses from (A) firekilled snags, which demonstrate lighter charring than (B) beetlekilled snags, at the Pole Creek Fire (2012), Oregon, USA. (A) The firekilled snag had no evidence of mountain pine beetle activity, and samples were taken from the charred bark and the wood under charred bark. (B) The beetle-killed snag had evidence of mountain pine beetle activity, and samples were taken from the charred bark and charred wood. Photos were taken during sampling in June 2018. Photographer credit: L. Matosziuk and A. Talucci

We adapted the BPCA methods developed by Dittmar (2008), Wiedemeier et al. (2013), and Wiedemeier et al. (2016). The BPCA method was developed by Glaser et al. (1998) and has since been refined (Brodowski et al. 2005; Dittmar 2008; Wiedemeier et al. 2013; Wiedemeier et al. 2016). The BPCA method is a time-intensive organic geochemical procedure and small sample sizes are common (e.g., Schneider et al. 2013); we have examined the reproducibility of duplicate analyses outlined in Matosziuk et al. (2019).

Briefly, samples containing $2 \mathrm{mg}$ of organic C were digested in $5 \mathrm{~mL}$ nitric acid at $170{ }^{\circ} \mathrm{C}$ for eight hours to break down the large aromatic structures that are characteristic of PyC into individual BPCAs. Samples were filtered through glass fiber filters (Whatman glass microfilters, grade GF/A; MilliporeSigma Corporation, St.
Louis, Missouri, USA), diluted to $50 \mathrm{~mL}$ with deionized water, flash-frozen with liquid nitrogen, and freeze-dried with a LabConco FreeZone Plus (LabConco Corporation, Kansas City, Missouri, USA). The residue was dissolved in $2 \mathrm{~mL}$ of $1 \mathrm{M}$ sodium hydroxide $(\mathrm{NaOH})$ and filtered using $0.45 \mu \mathrm{m}$ nylon syringe filters (Whatman Puradisc; MilliporeSigma Corporation). A $1 \mathrm{~mL}$ aliquot of this solution was transferred to a new vial and spiked with $600 \mu \mathrm{L}$ of $2 \mathrm{M}$ hydrochloric acid $(\mathrm{HCl})$. High performance liquid chromatography (HPLC) was used to quantify individual BPCAs. Specifically, samples were analyzed using a Shimadzu LC-10AD equipped with an SPD-M20A photodiode array (Shimadzu Scientific Instruments, Columbia, Maryland, USA) capable of measuring wavelengths between 190 and $400 \mathrm{~nm}$. An Agilent Poroshell 120 SB-C18 column (Agilent, Santa Clara, California, USA) was used with a mobile phase consisting of a binary gradient of phosphoric acid $\left(\mathrm{H}_{3} \mathrm{PO}_{4} ; 2 \%\right.$ in water) and acetonitrile (Wiedemeier et al. 2013). External standards of pure BPCA solutions were used to construct 6-point calibration curves to determine the concentrations of individual BPCAs.

We assessed PyC on beetle-killed and fire-killed snags by measuring the concentration and degree of aromatic condensation. The concentration of $\mathrm{PyC}$ was measured as grams of BPCA per kilogram of $\mathrm{C}$ ( $\mathrm{g}$ BPCA per $\mathrm{kg} \mathrm{C}$ ), referred to as the proportion of $\mathrm{C}(\mathrm{PyC}: \mathrm{kg} \mathrm{C})$, and as grams of BPCA per kilogram of material (g BPCA per $\mathrm{kg}$ material), referred to as the proportion of mass (PyC : kg material). The degree of aromatic condensation was quantified using the Aromatic Condensation Index (ACI), which is defined as the concentration of benzene hexacarboxylic acid (B6CA) as a proportion of all BPCAs (Schneider et al. 2010; Schneider et al. 2011; Schneider et al. 2013). Additional description is available in Matosziuk et al. (2019).

\section{Statistical analyses}

We tested for a difference in PyC between samples from beetle-killed and fire-killed snags. We pooled bark and wood samples for analyses because of the small sample size. Exploratory data analysis showed substantial differences in BPCA measures between bark and wood but much greater differences overall between beetle-killed and fire-killed snags (Fig. 3), supporting our pooling of samples for this work. We conducted three analyses, one for each response variable-PyC per C, PyC per material, and $\mathrm{ACI}-$ to evaluate the differences between beetlekilled and fire-killed snags. We used a Welch $t$-test for unequal variance (Welch 1947) to test for a difference in means with the stats package ( $\mathrm{R}$ Core Team 2020). We assessed assumptions for all models by visually inspecting the residuals, which appeared to be adequately met. All statistical analyses were conducted 

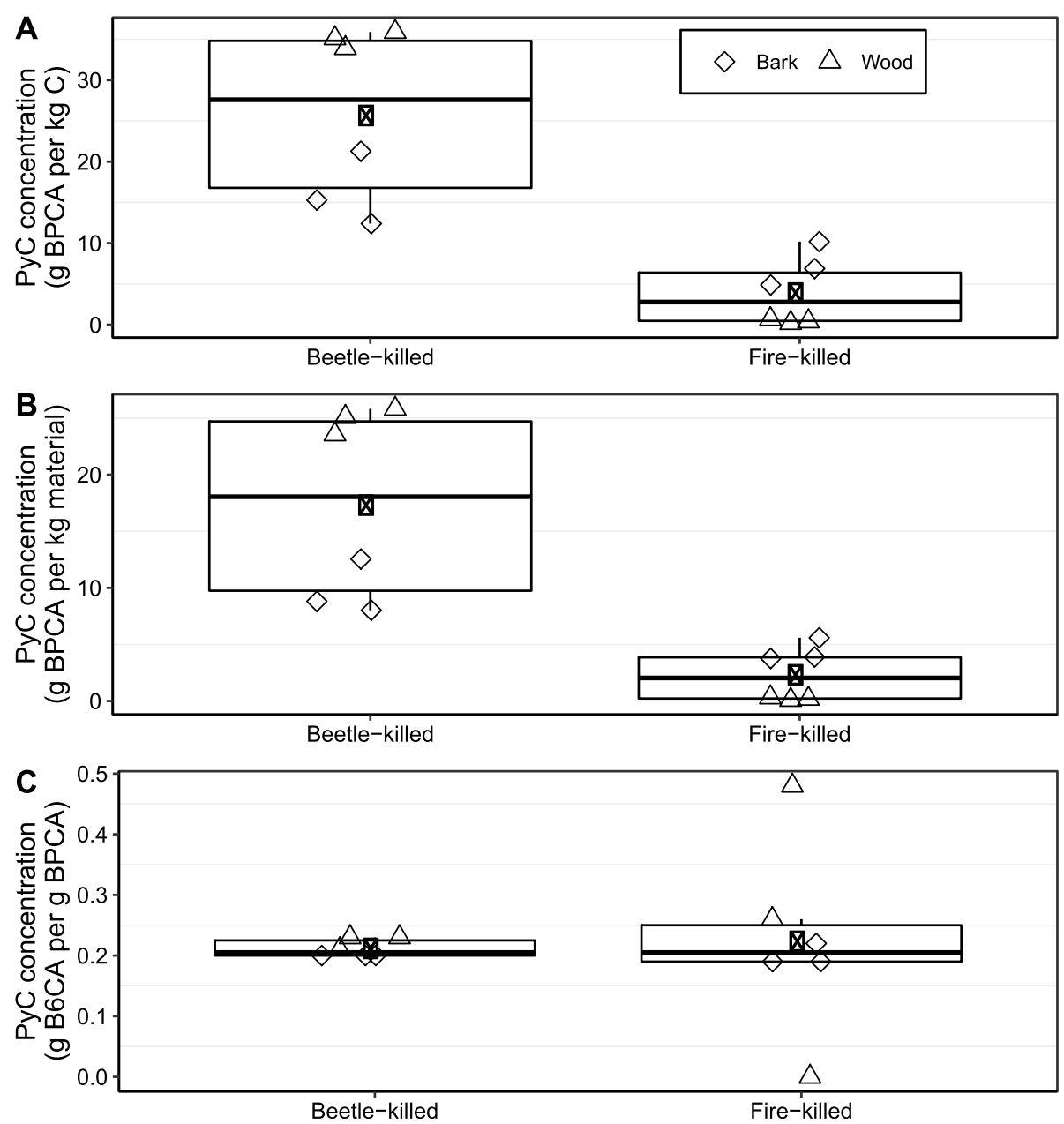

Fig. 3 Differences in pyrogenic carbon (PyC) for charred bark and wood from beetle-killed snags and fire-killed snags that were sampled at the Pole Creek Fire (2012), Oregon, USA, in June 2018. A Welch $t$-test for unequal variance was performed to test for a difference in mean Benzene Polycarboxylic Acid (BPCA) concentrations between beetle-killed $(n=6)$ and fire-killed $(n=6)$ snags. Each panel shows the mean (point), raw data split as bark (diamonds) and wood (triangles) samples, and the boxplot distribution. (A) Beetle-killed snags had a greater concentration of PyC than fire-killed snags, with a difference of $21.8 \mathrm{~g}$ BPCA per kg Carbon (C; 95\% confidence interval $=10.6$ to 33, $P=0.003)$ and (B) a difference of $15 \mathrm{~g}$ BPCA per $\mathrm{kg}$ material (95\% confidence interval $=6.2$ to $23.8, P=0.006)$. (C) For the Aromatic Condensation Index $(\mathrm{ACl})$, there was no difference between beetle-killed and fire-killed snags. However, the low concentration of BPCA in fire-killed snags (A, B) suggests that the overall concentration of benzene hexacarboxylic acid (B6CA) in fire-killed snags is lower than in beetle-killed snags. The difference in PyC concentrations between beetle-killed and fire-killed snags demonstrates an important compound effect of short-interval beetle-fire disturbances

in $\mathrm{R}$ statistical computing software version 3.6 .3 ( $\mathrm{R}$ Core Team 2020). We considered $P<0.05$ as convincing evidence of a relationship, and $0.05<P<0.10$ as suggestive of a relationship to minimize the potential of a Type II error.

\section{Results}

The concentration of $\mathrm{PyC}$ was greater on samples from beetle-killed snags compared to fire-killed snags (Fig. 3). On a per $\mathrm{C}$ basis, beetle-killed snags had an estimated mean ( $\pm \mathrm{SD}$ ) of $25.7 \pm 10.6 \mathrm{~g}$ BPCA per $\mathrm{kg} \mathrm{C}$, while firekilled snags had an estimated mean of $3.9 \pm 4.1 \mathrm{~g}$ BPCA per $\mathrm{kg} \mathrm{C}$. Beetle-killed snags exhibited over five times the amount of g BPCA per $\mathrm{kg} \mathrm{C}$ compared to fire-killed snags, with an estimated difference in the means $( \pm \mathrm{SE})$ of $21.8 \pm 4.7 \mathrm{~g}$ BPCA per $\mathrm{kg} \mathrm{C}(P=0.003$; Fig. 3a). On a per mass basis, beetle-killed snags had an estimated mean $( \pm \mathrm{SD})$ of $17.3 \pm 8.4 \mathrm{~g}$ BPCA per kg material, while fire-killed snags had an estimated mean of $2.3 \pm 2.4 \mathrm{~g}$ BPCA per kg material. Beetle-killed snags exhibited over seven times the amount of g BPCA per $\mathrm{kg}$ material compared to fire-killed snags, with an estimated difference in the means $( \pm \mathrm{SE})$ of $15.0 \pm 3.6 \mathrm{~g}$ BPCA per $\mathrm{kg}$ material $(P=0.006$; Fig. $3 \mathrm{~b})$. There was no difference between beetle-killed and fire-killed snags in terms of the degree of aromatic condensation, measured as ACI. Beetlekilled snags had an estimated mean $( \pm \mathrm{SD}) \mathrm{ACI}$ of 0.21 $\pm 0.01 \mathrm{~g}$ B6CA per g BPCA, while fire-killed snags had 
an estimated mean ACI of $0.22 \pm 0.15 \mathrm{~g}$ B6CA per $\mathrm{g}$ BPCA. For ACI, the estimated difference in means $( \pm$ $\mathrm{SE})$ between mortality agents was $-0.012 \pm 0.063 \mathrm{~g}$ B6CA per g BPCA ( $P=0.86$ : Fig. $3 c)$.

\section{Discussion}

Our data shows how beetle-killed snags provide an added boost of PyC compared to fire-killed snags, revealing an important compound effect from the interaction of beetle outbreak and wildfire in forest ecosystems. This evaluation provides new insight to the $C$ cycle based on a molecular marker method, BPCA, that examines the type of molecules that are characteristic of PyC. Our small sample size and focus on one component of $\mathrm{PyC}$ in the forest limits the ecological inference, and scaling to a landscape measurement was outside the scope of the study, but our findings provide a crucial step for understanding how disturbance history affects $\mathrm{PyC}$ and the global $\mathrm{C}$ cycle. The BPCA metric shows distinct differences between beetle-killed and fire-killed snags in terms of the concentration of PyC on a per $\mathrm{C}$ and per mass basis. These differences only acknowledge one PyC forest pool but likely have broad influences across forest ecosystem functions, including decomposition, $\mathrm{C}$ dynamics, and nutrient cycling, all of which operate through deadwood and warrant further investigation.

Our study offers insight into the molecular structure of char on snags generated from the fuel conditions created by short-interval beetle-fire disturbances, which has received limited attention in previous work. While several studies scale the surface area of char on snags to quantify charcoal production to landscape scales, they do so without an elemental or molecular analysis, which informs the type of PyC (e.g., Makoto et al. 2012; Donato et al. 2016; Ward et al. 2017). These studies note heavy charring and increased area charred on pre-fire snags from either prior beetle kill or prior wildfire (Makoto et al. 2012; Donato et al. 2016; Ward et al. 2017), which could be attributed to the interval between disturbance events resulting in lower moisture content in snags than in live trees (Stockstad 1979). Previous studies of the role of char left by the interaction of beetle outbreaks and wildfires investigate events with intervals of three to 14 years (Makoto et al. 2012; Harvey et al. 2014; Talucci and Krawchuk 2019), while here, the interval was eight to 15 years between outbreak and wildfire (McConnell et al. 2000; ADS 2005). Further investigation is warranted to understand the effect of disturbance intervals on PyC production since the time between the initial tree mortality event and wildfire is likely a crucial component in conjunction with wildfire conditions (e.g., intensity, severity, weather) that contribute to heavy charring and can be linked with molecular PyC.
There was no difference in aromatic condensation between samples from beetle-killed and fire-killed snags, as assessed with ACI. It is unclear whether the low overall concentrations of BPCA on the fire-killed snags may have obfuscated any signal for the ratio of B6CA to BPCA (ACI). Since our data showed similar condensation levels between beetle-killed and fire-killed snags, this suggests a comparable thermal exposure (Schneider et al. 2013). We had expected differences in moisture levels between live and dead trees at the time of the fire (Stockstad 1979) to result in higher condensation levels in beetle-killed compared to fire-killed snags. Elemental analyses that evaluate aromaticity show variability in the atomic ratios for charred bark across difference studies (Schneider et al. 2013; Uhelski and Miesel 2017), which could be attributed to fire behavior characteristics that influence pyrolysis and would vary by fire event. Our samples were acquired from the base of the snags where fire intensity and thermal exposure are greater than in the canopy (Schneider et al. 2013), and the base of snags has been linked to greater aromaticity than in the canopy (Uhelski and Miesel 2017). Further study is required to understand potential differences in $\mathrm{C}$ condensation for short-interval disturbances, given the importance of this feature to biogeochemical cycling.

\section{Broader influences}

Deadwood legacies are critical components of forest ecosystems that serve numerous functions, and the distinct PyC signature on beetle-killed snags motivates the development of broader thinking about its potential role in forest ecosystems (Fig. 4). Short-interval disturbances create distinctive fuel conditions by converting forests into an abundance of standing dead snags that result in altered structural legacies post fire than what would be expected after a fire burns through live forests. This change in post-fire structural legacies can influence post-fire biodiversity (Fig. 4). For example, certain woodpecker species are post-fire specialists reliant on standing and downed deadwood that serves as habitat and food sources (Swanson et al. 2011), but the landscape of standing and downed deadwood can be reduced and simplified by short-interval disturbances (Makoto et al. 2012; Donato et al. 2016; Talucci and Krawchuk 2019; Turner et al. 2019). A simplified physical structure, or architecture, associated with burned, beetle-killed snags (Talucci and Krawchuk 2019) could reduce perching habitat for birds, nesting material, shade cover, and the interception of precipitation (Fig. 4). In areas with substantial mortality from beetle outbreaks that then burn severely, beetle-killed snags may become fully encapsulated with heavy charring (Makoto et al. 2012; Talucci and Krawchuk 2019), which could equate to more PyC 


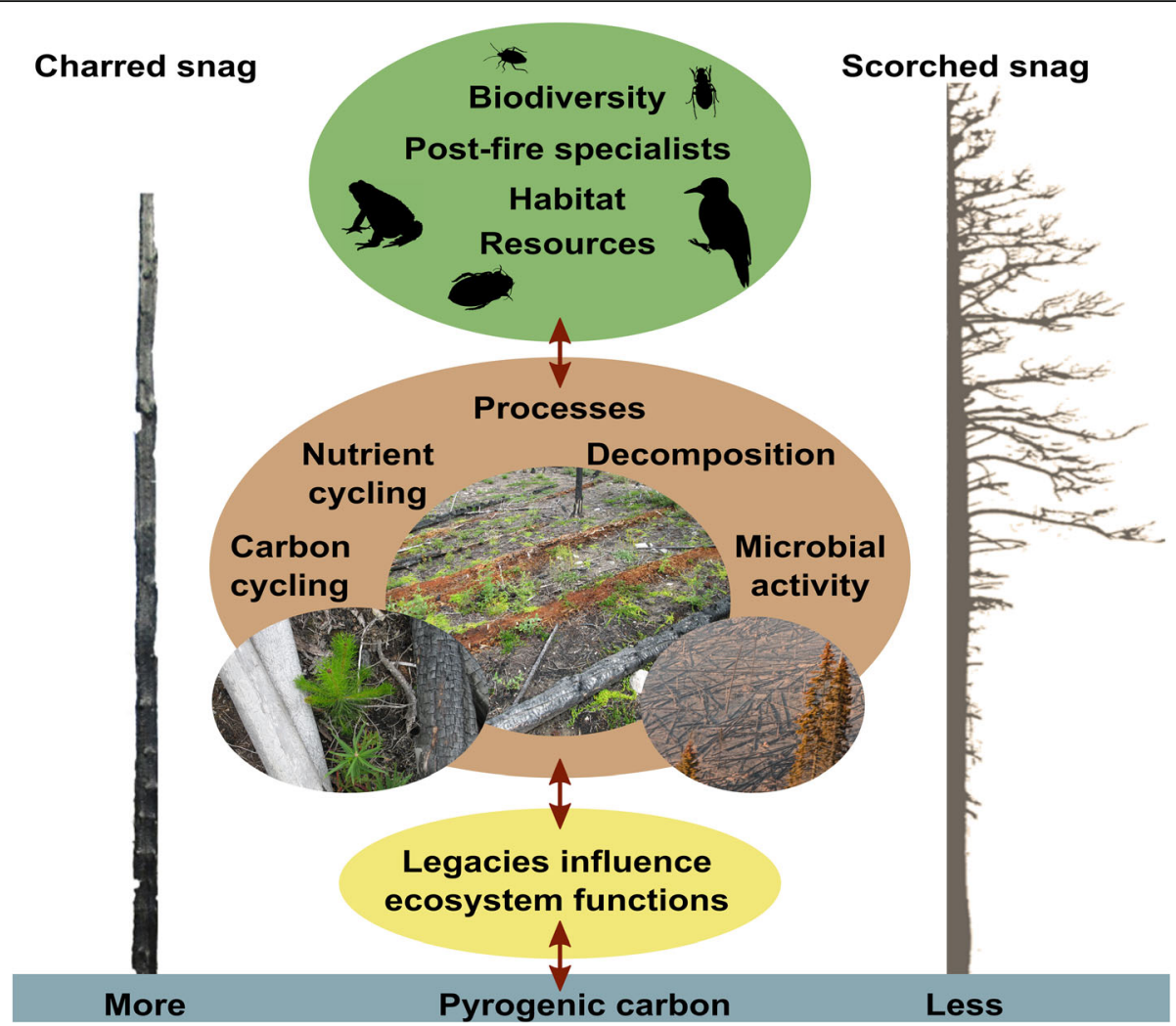

Fig. 4 A conceptual framework of how post-fire legacies and pyrogenic carbon (PyC) influence ecosystem functions. The concentration of PyC was greater on beetle-killed snags (left) compared to fire-killed snags (right), creating an ecological legacy that has the potential to function differently. Beetle-killed snags are architecturally distinct from fire-killed snags, further contributing ecological differences. Forest conditions where a substantial number of beetle-killed snags burn and produce heavily charred snags could influence ecosystem processes that operate through deadwood including decomposition, microbial activity, nutrient cycling, and resources for insects and birds

that potentially affects resources for high-severity postfire specialists, such as saproxylic insects and fungi, so that it differs from that offered by fires burning through live forests (Nappi et al. 2010). This begs the question of how patches of forest with a large proportion of snags killed before fire, either by insect outbreaks, drought, wind, or fire, alter the biodiversity of post-fire specialists.

Decomposition, nutrient cycling, and microbial activity are all ecosystem processes that operate through the deadwood pool (Harmon 2001) that could be altered by a change to the PyC stores. The breakdown of beetlekilled snags through weathering, peeling, and cracking of the charred layer could mobilize PyC from standing snags to ground (Manies et al. 2005) and into soil organic matter (Michelotti and Miesel 2015; Pingree and DeLuca 2017). Since beetle-killed snags are shown to have more $\mathrm{PyC}$ than fire-killed snags, they could contribute additional PyC to soils over time, which in turn could slow turnover times for decomposition processes and subsequent $\mathrm{C}$ cycling (Bird et al. 2015; Pingree and DeLuca 2017), as well as influence the nitrogen cycle (DeLuca et al. 2006). Further investigation is warranted to fully understand how charring on snags from short- interval disturbances influences decomposition, nutrient cycling, and microbial activity.

\section{Conclusion}

This study found $\mathrm{PyC}$ concentrations to be greater in samples from beetle-killed snags than in fire-killed snags, pointing to an important interaction effect for shortinterval beetle-fire disturbances. While this study was limited to a single fire event and sampling in individual trees that burned at moderate to high severity, it provides insight into differences in $\mathrm{PyC}$ on snags with different disturbance histories. The abundance of heavily charred snags from a fire burning through landscapes with high levels of existing mortality from insect outbreaks, drought, wind, and wildfire events is becoming a more common legacy for contemporary western North American forests, with potential to affect PyC. Drivers and outcomes of $\mathrm{PyC}$ formation from short-interval disturbances is a burgeoning area of research that requires further investigation into effects on ecosystems functions, including biogeochemical cycling and ecological consequences for forests. 


\section{Acknowledgements}

We thank the Landscape Fire and Conservation Science Research Group for their thoughtful insight and expertise throughout this project. We thank A. Merschel for his assistance collecting field samples associated with earlier experiments, and T. Hudson and D. Blunk with the CIRE and Propulsion Labs at Oregon State University for assistance with some initial exploration of burning wood. We thank A. Muldoon for consultation on statistical analyses. We thank S. Perakis, US Geological Survey, for feedback that improved this manuscript. We thank the anonymous reviewers whose feedback greatly improved this manuscript.

\section{Authors' contributions}

AT, MK, LM, and JH conceived the study. AT, MK, and LM developed the data collection methods. AT and LM collected the data. LM developed laboratory protocols and analyzed samples in the lab. AT analyzed the data. AT wrote the first draft of the manuscript and all co-authors contributed substantially. All authors read and approved the final manuscript.

\section{Funding}

This research was supported by funding from Oregon State University College of Forestry and partial support from the National Science Foundation under award number $1733885(\mathrm{JH})$.

\section{Availability of data and materials}

Data and code for analyses and figures are archived in a GitHub repository on Zenodo (https://doi.org/10.5281/zenodo.3959377).

\section{Ethics approval and consent to participate}

Not applicable.

\section{Consent for publication}

Not applicable.

\section{Competing interests}

The authors declare that they have no competing interests.

\section{Author details}

'Department of Geography, Colgate University, 13 Oak Drive, Hamilton, New York 13346, USA. ${ }^{2}$ Department of Forest Ecosystems and Society, Oregon State University, 3100 SW Jefferson Way, Corvallis, Oregon 97331, USA. ${ }^{3}$ Department of Forest Engineering and Management, Oregon State University, 3100 SW Jefferson Way, Corvallis, Oregon 97331, USA.

Received: 1 June 2020 Accepted: 7 August 2020

Published online: 11 September 2020

\section{References}

ADS. 2005. 2005 Aerial insect and disease survey USGS 100k Quad: Bend - 44121A1; 4J. Portland: USDA Forest Service, Region 6.

Agne, M.C., T. Woolley, and S. Fitzgerald. 2016. Fire severity and cumulative disturbance effects in the post-mountain pine beetle lodgepole pine forests of the Pole Creek Fire. For Ecol Manag 366: 73-86. https://doi.org/10.1016/j. foreco.2016.02.004

Bentz, B.J., Régnière, J., Fettig, C.J., et al. 2010. Climate change and bark beetles of the western United States and Canada: direct and indirect effects. BioScience 60: 602-613. https://doi.org/10.1525/bio.2010.60.8.6.

Bird, M.I., J.G. Wynn, G. Saiz, et al. 2015. The pyrogenic carbon cycle. Annu Rev Earth Planet Sci 43: 273-298. https://doi.org/10.1146/annurev-earth-060614-105038.

Brodowski, S., A. Rodionov, L. Haumaier, et al. 2005. Revised black carbon assessment using benzene polycarboxylic acids. Org Geochem 36: 1299-1310. https://doi.org/10.1016/j.orggeochem.2005.03.011.

Buma, B., R.E. Poore, and C.A. Wessman. 2014. Disturbances, their interactions, and cumulative effects on carbon and charcoal stocks in a forested ecosystem. Ecosystems 17: 947-959. https://doi.org/10.1007/s10021-014-9770-8.

Campbell, J., D. Donato, D. Azuma, and B. Law. 2007. Pyrogenic carbon emission from a large wildfire in Oregon, United States. J Geophys Res 112. https://doi. org/10.1029/2007JG000451

DeLuca, T.H., M.D. MacKenzie, M.J. Gundale, and W.E. Holben. 2006. WildfireProduced Charcoal Directly Influences Nitrogen Cycling in Ponderosa Pine Forests. Soil Sci Soc Am J 70: 448-453. https://doi.org/10.2136/sssaj2005.0096.
Dittmar, T. 2008. The molecular level determination of black carbon in marine dissolved organic matter. Org Geochem 39: 396-407. https://doi.org/10.1016/j. orggeochem.2008.01.015.

Donato, D.C., J.L. Campbell, J.B. Fontaine, and B.E. Law. 2009. Quantifying char in postfire woody detritus inventories. Fire Ecol 5: 104-115. https://doi.org/10. 4996/fireecology.0502104.

Donato, D.C., J.B. Fontaine, and J.L. Campbell. 2016. Burning the legacy? Influence of wildfire reburn on dead wood dynamics in a temperate conifer forest. Ecosphere 7: e01341. https://doi.org/10.1002/ecs2.1341.

Eidenshink, J., B. Schwind, K. Brewer, et al. 2007. A Project for Monitoring Trends in Burn Severity. Fire Ecol 3: 3-21. https://doi.org/10.4996/fireecology.0301003.

Flannigan, M., Stocks, B., Turetsky, M., Wotton, M. 2009. Impacts of climate change on fire activity and fire management in the circumboreal forest. Global Change Biology 15: 549-560. https://doi.org/10.1111/j.1365-2486.2008.01660.x.

Glaser, B., L. Haumaier, G. Guggenberger, and W. Zech. 1998. Black carbon in soils: the use of benzenecarboxylic acids as specific markers. Org Geochem 29: 811 8-19. https://doi.org/10.1016/S0146-6380(98)00194-6.

Hammes, K., M.W.I. Schmidt, R.J. Smernik, et al. 2007. Comparison of quantification methods to measure fire-derived (black/elemental) carbon in soils and sediments using reference materials from soil, water, sediment and the atmosphere. Glob Biogeochem Cycles 21. https://doi.org/10.1029/ 2006GB002914.

Harmon, M.E. 2001. Moving towards a new paradigm for woody detritus management. Ecol Bull 49: 269-278.

Harvey, B.J., Donato, D.C., Romme, W.H., Turner, M.G. (2013). Influence of recent bark beetle outbreak on fire severity and postfire tree regeneration in montane Douglas-fir forests. Ecology 94: 2475-2486. https://doi.org/10.1890/ 13-0188.1.

Harvey, B.J., D.C. Donato, and M.G. Turner. 2014. Recent mountain pine beetle outbreaks, wildfire severity, and postfire tree regeneration in the US Northern Rockies. Proc Natl Acad Sci 111: 15120-15125. https://doi.org/10.1073/pnas. 1411346111.

Hyde, J.C., A.M.S. Smith, R.D. Ottmar, et al. 2011. The combustion of sound and rotten coarse woody debris: a review. Int J Wildland Fire 20: 163. https://doi. org/10.1071/WF09113.

Jones, M.W., C. Santín, G.R. van der Werf, and S.H. Doerr. 2019. Global fire emissions buffered by the production of pyrogenic carbon. Nat Geosci 12: 742-747. https://doi.org/10.1038/s41561-019-0403-x

Makoto, K., N. Kamata, N. Kamibayashi, et al. 2012. Bark-beetle-attacked trees produced more charcoal than unattacked trees during a forest fire on the Kenai Peninsula, Southern Alaska. Scand J For Res 27: 30-35. https://doi.org/ 10.1080/02827581.2011.619566.

Manies, K.L., J.W. Harden, B.P. Bond-Lamberty, and K.P. O'Neill. 2005. Woody debris along an upland chronosequence in boreal Manitoba and its impact on long-term carbon storage. Can J For Res 35: 472-482. https://doi.org/10. 1139/×04-179.

Masiello, C.A. 1998. Black carbon in deep-sea sediments. Science 280: 1911-1913. https://doi.org/10.1126/science.280.5371.1911.

Matosziuk, L.M., Y. Alleau, B.K. Kerns, et al. 2019. Effects of season and interval of prescribed burns on pyrogenic carbon in ponderosa pine stands in the southern Blue Mountains, Oregon, USA. Geoderma 348: 1-11. https://doi.org/ 10.1016/j.geoderma.2019.04.009.

McBeath, A.V., R.J. Smernik, M.P.W. Schneider, et al. 2011. Determination of the aromaticity and the degree of aromatic condensation of a thermosequence of wood charcoal using NMR. Org Geochem 42: 1194-1202. https://doi.org/ 10.1016/j.orggeochem.2011.08.008.

McConnell, T.J., E.W. Johnson, and B. Burns. 2000. A guide to conducting aerial sketchmapping surveys. Fort Collins: USDA Forest Service.

Michelotti, L., and J. Miesel. 2015. Source Material and Concentration of WildfireProduced Pyrogenic Carbon Influence Post-Fire Soil Nutrient Dynamics. Forests 6: 1325-1342. https://doi.org/10.3390/f6041325.

MTBS. 2016. Monitoring Trends in Burn Severity assessment of Fire Information: or4417812169920120909. Sioux Falls: U.S. Geological Survey and U.S. Forest Service.

Nappi, A., P. Drapeau, M. Saint-Germain, and V.A. Angers. 2010. Effect of fire severity on long-term occupancy of burned boreal conifer forests by saproxylic insects and wood-foraging birds. Int I Wildland Fire 19: 500. https://doi.org/10.1071/WF08109.

Pingree, M.R.A., and T.H. DeLuca. 2017. Function of wildfire-deposited pyrogenic carbon in terrestrial ecosystems. Front Environ Sci 5: 53. https://doi.org/10. 3389/fenvs.2017.00053. 
R Core Team. 2020. R: A language and environment for statistical computing. Version 3.6.3. Vienna: R Foundation for Statistical Computing.

Raffa, K.F., Aukema, B.H., Bentz, B.J., Carroll, A.L., Hicke, J.A., Turner, M.G., Romme, W.H. 2008. Cross-scale drivers of natural disturbances prone to anthropogenic amplification: the dynamics of bark beetle eruptions. BioScience 58: 501-517. https://doi.org/10.1641/B580607.

Randerson, J.T., Y. Chen, G.R. van der Werf, et al. 2012. Global burned area and biomass burning emissions from small fires: BURNED AREA FROM SMALL FIRES. J Geophys Res Biogeosciences 117. https://doi.org/10.1029/ 2012JG002128.

Santín, C., S.H. Doerr, E.S. Kane, et al. 2016. Towards a global assessment of pyrogenic carbon from vegetation fires. Glob Change Biol 22: 76-91. https:// doi.org/10.1111/gcb.12985.

Santín, C., S.H. Doerr, C.M. Preston, and G. González-Rodríguez. 2015. Pyrogenic organic matter production from wildfires: a missing sink in the global carbon cycle. Glob Change Biol 21: 1621-1633. https://doi.org/10.1111/gcb.12800.

Schmidt, M.W.I., J.O. Skjemstad, C.I. Czimczik, et al. 2001. Comparative analysis of black carbon in soils. Glob Biogeochem Cycles 15: 163-167. https://doi.org/10. 1029/2000GB001284.

Schneider, M.P.W., M. Hilf, U.F. Vogt, and M.W.I. Schmidt. 2010. The benzene polycarboxylic acid (BPCA) pattern of wood pyrolyzed between $200^{\circ} \mathrm{C}$ and $1000^{\circ} \mathrm{C}$. Org Geochem 41: 1082-1088. https://doi.org/10.1016/j.orggeochem. 2010.07.001.

Schneider, M.P.W., L.A. Pyle, K.L. Clark, et al. 2013. Toward a "molecular thermometer" to estimate the charring temperature of wildland charcoals derived from different biomass sources. Environ Sci Technol 47: 11490-11495. https://doi.org/10.1021/es401430f

Schneider, M.P.W., R.H. Smittenberg, T. Dittmar, and M.W.I. Schmidt. 2011. Comparison of gas with liquid chromatography for the determination of benzenepolycarboxylic acids as molecular tracers of black carbon. Org Geochem 42: 275-282. https://doi.org/10.1016/j.orggeochem.2011.01.003.

Singh, N., S. Abiven, M.S. Torn, and M.W.I. Schmidt. 2012. Fire-derived organic carbon in soil turns over on a centennial scale. Biogeosciences 9: 2847-2857. https://doi.org/10.5194/bg-9-2847-2012.

Stockstad, D.S. 1979. Spontaneous and piloted ignition of rotten wood. Ogden: USDA Forest Service.

Swanson, M.E., J.F. Franklin, R.L. Beschta, et al. 2011. The forgotten stage of forest succession: early-successional ecosystems on forest sites. Front Ecol Environ 9: 117-125. https://doi.org/10.1890/090157.

Talucci, A.C., and M.A. Krawchuk. 2019. Dead forests burning: the influence of beetle outbreaks on fire severity and legacy structure in sub-boreal forests. Ecosphere 10: e02744. https://doi.org/10.1002/ecs2.2744.

Torn, M.S., P.M. Vitousek, and S.E. Trumbore. 2005. The influence of nutrient availability on soil organic matter turnover estimated by incubations and radiocarbon modeling. Ecosystems 8: 352-372. https://doi.org/10.1007/ s10021-004-0259-8.

Turner, M.G., K.H. Braziunas, W.D. Hansen, and B.J. Harvey. 2019. Short-interval severe fire erodes the resilience of subalpine lodgepole pine forests. Proc Natl Acad Sci 116: 11319-11328. https://doi.org/10.1073/pnas.1902841116.

Uhelski, D., and J.R. Miesel. 2017. Physical location in the tree during forest fire influences element concentrations of bark-derived pyrogenic carbon from charred jack pines (Pinus banksiana Lamb.). Org Geochem 110: 87-91. https:// doi.org/10.1016/j.orggeochem.2017.04.014.

Ward, A., C.A. Cansler, and A.J. Larson. 2017. Black carbon on coarse woody debris in once- and twice-burned mixed-conifer forest. Fire Ecol 13: 143-147. https://doi.org/10.4996/fireecology.130288796.

Welch, B.L. 1947. The Generalization of 'Student's' Problem when Several Different Population Variances are Involved. Biometrika 34: 28. https://doi.org/10.2307/ 2332510.

Wiedemeier, D.B., M.D. Hilf, R.H. Smittenberg, et al. 2013. Improved assessment of pyrogenic carbon quantity and quality in environmental samples by highperformance liquid chromatography. J Chromatogr A 1304: 246-250. https:// doi.org/10.1016/j.chroma.2013.06.012

Wiedemeier, D.B., S.Q. Lang, M. Gierga, et al. 2016. Characterization, quantification and compound-specific isotopic analysis of pyrogenic carbon using benzene polycarboxylic acids (BPCA). J Vis Exp 53922. https://doi.org/10.3791/53922.

\section{Publisher's Note}

Springer Nature remains neutral with regard to jurisdictional claims in published maps and institutional affiliations.

\section{Submit your manuscript to a SpringerOpen ${ }^{\circ}$ journal and benefit from:}

- Convenient online submission

- Rigorous peer review

- Open access: articles freely available online

- High visibility within the field

- Retaining the copyright to your article

Submit your next manuscript at $\boldsymbol{\nabla}$ springeropen.com 